\title{
Nerve mediated relaxation of the human internal anal sphincter: the role of nitric oxide
}

Terence O’Kelly, Alison Brading, Neil Mortensen

\begin{abstract}
The aim of this study was to determine if nitric oxide (NO) is the non-adrenergic, noncholinergic neurotransmitter, released by enteric inhibitory nerves, which mediates relaxation of the human internal anal sphincter. Isolated muscle strips were mounted for isometric tension recording in superfusion organ baths. Sodium nitroprusside, an exogenous donor of NO, relaxed the strips in a concentration dependent manner. In the presence of atropine and guanethidine, transmural field stimulation produced tetrodotoxin sensitive relaxations, which were inhibited in a dose dependent and enantiomer specific manner by antagonists of NO synthase; completely by L-nitroarginine and partially by $\mathrm{L}-\mathrm{N}$-monomethyl arginine. The effect of these antagonists was reversed by $L$-arginine but not D-arginine. Oxyhaemoglobin, a scavenger of nitric oxide, also abolished the relaxations but methaemoglobin had no such effect. These results strongly suggest that NO is, or is very closely associated with, the non-adrenergic, non-cholinergic neurotransmitter mediating neurogenic relaxation of the human internal anal sphincter.

(Gut 1993; 34: 689-693)
\end{abstract}

It has been recognised for over a century that the internal anal sphincter relaxes in response to rectal distension, a phenomenon called the rectanal inhibitory reflex. ${ }^{12}$ The reflex is a component of normal anorectal behaviour and its integrity is assessed routinely during the investigation of patients with disordered anorectal function. Despite this we know little of the mechanisms, neuronal and muscular, that are involved.

It is established that the nerves mediating the rectoanal inhibitory reflex lie wholly in the wall of the gut and are thus known as enteric (intrinsic) inhibitory neurons..$^{2-4}$ They descend from the rectum to the internal anal sphincter and do not use the classical neurotransmitter substances, acetylcholine and noradrenaline. ${ }^{3}$ They are thus classified as non-adrenergic, noncholinergic (NANC) nerves. Several NANC neurotransmitters have been implicated here, for example adenosine triphosphate and vasoactive intestinal polypeptide, but in humans, evidence supporting their involvement has not been substantiated..$^{56}$

Implausible as it might seem at first, there is now good evidence that nitric oxide (NO) is an important endogenous bioactive substance..$^{7-9}$ It has been identified as a neurotransmitter in the gastrointestinal tract, ${ }^{9-19}$ and has been implicated in nerve mediated relaxation of the internal anal sphincter. ${ }^{20-25}$

Nitric oxide is synthesised from L-arginine in a reaction catalysed by NO synthase. This enzyme exhibits a high degree of substrate specificity (NO is not produced from Darginine) and is dependent on several cofactors, among which are $\mathrm{Ca}^{2+}$, calmodulin, and reduced nicotinamide adenine dinucleotide phosphate. Nitric oxide is freely soluble, diffuses rapidly, and has a short half life (three seconds), being inactivated by formation of $\mathrm{NO}_{3}{ }^{-}$after contact with the superoxide anion, $\mathrm{O}_{2}{ }^{-}$. It exerts its effects by binding to cytosolic guanylate cyclase and stimulating the production of cyclic guanosine monophosphate.

In humans, the hypothesis that NO is an inhibitory neurotransmitter in the internal anal sphincter is based on results presented in a brief report, ${ }^{25}$ which showed that $\mathrm{N}$-nitro-L-arginine, a potent antagonist of NO synthase, abolished NANC nerve mediated relaxation in isolated sphincter tissue. We have investigated the involvement of $\mathrm{NO}$ in greater detail and have examined the effects of exogenous NO, inhibitors of NO synthase, and oxyhaemoglobin, a scavenger of NO, on the behaviour of isolated strips of human internal anal sphincter in vitro.

\section{Methods}

Sphincter tissue was taken from patients (four men, seven women; median age 69 (range 57-82) years) undergoing abdominoperineal resection of the rectum and anal canal for low lying rectal carcinoma. With a dissecting microscope, the epithelium of the anal canal was removed together with the submucosa. Strips of the distal internal anal sphincter measuring $1 \times 1 \times 10 \mathrm{~mm}$ and containing parallel muscle bundles were prepared and mounted for isometric tension recording in superfusion organ baths (capacity $0.2 \mathrm{ml}$ ). The strips were continuously superfused with $\mathrm{Krebs}$ solution $\left(37^{\circ} \mathrm{C}\right)$ at a rate of $1 \mathrm{ml} /$ min. Atropine $\left(10^{-6} \mathrm{M}\right)$ and guanethidine $\left(3 \times 10^{-6} \mathrm{M}\right)$ were present throughout to abolish cholinergic and adrenergic neurotransmission. Drugs and other agents being investigated were added to the Krebs solution before its entry into the baths. Recessed platinum ring electrodes $1 \mathrm{~cm}$ apart were used for intrinsic nerve stimulation (impulses of $10 \mathrm{~V}, 0.5 \mathrm{~ms}$ duration, frequency $1-30 \mathrm{~Hz}$ for 1 second - see results). The apparatus allowed six strips to be studied simultaneously. Tension was measured by Pioden transducers and recorded by a six channel Teckman pen recorder. The strips were initially placed under $1.0 \mathrm{~g}$ resting tension and allowed to equilibrate for at least an hour before the start of 

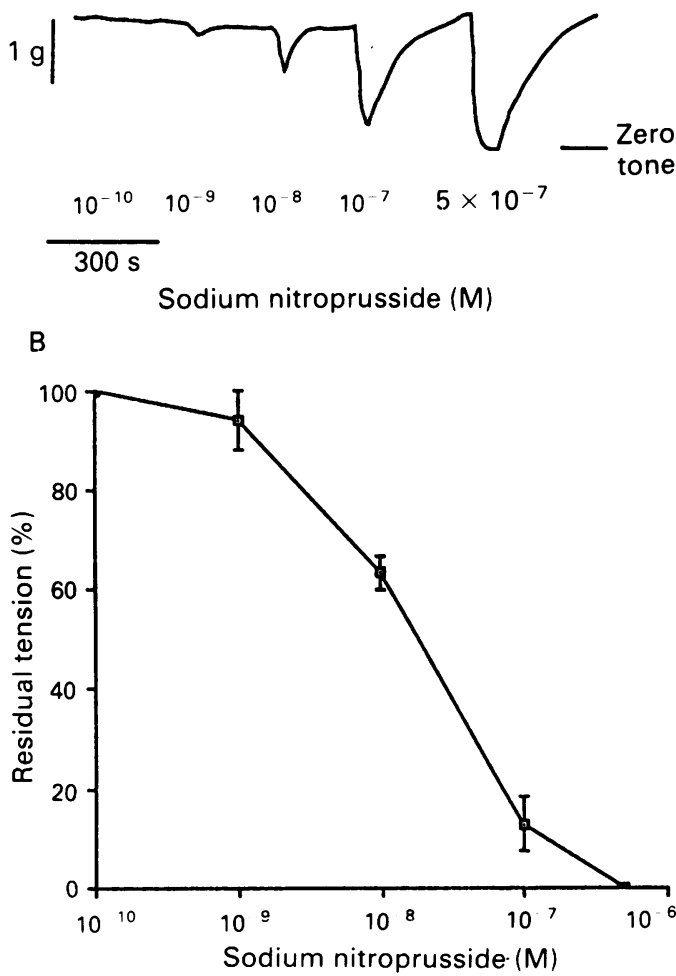

Figure 1: Effect of sodium nitroprusside on isolated strips of human internal anal sphincter, shown in the form of a characteristic trace $(A)$ and a cumulative dose response curve for 18 strips $(B)$. Relaxation is expressed in terms of the residual tone left in the strips after application of the drug. Zero tone in this and subsequent figures is that present in calcium free solution.

experiments. During this time, the strips contracted spontaneously and developed a high level of myogenic tone (mean SEM) $=0.48(0.04)$ $\mathrm{g} / \mathrm{mg}$ tissue; baseline is residual tone present in calcium free solution).

Krebs solution contained $120 \mathrm{mM} \mathrm{NaCl}, 5.9$ $\mathrm{mM} \mathrm{KCl}, 15.4 \mathrm{mM} \mathrm{NaHCO} 3,1 \mathrm{mM} \mathrm{NaH} \mathrm{PO}_{4}$, $2.5 \mathrm{mM} \mathrm{CaCl}$, and $11 \mathrm{mM}$ glucose. Solutions were equilibrated with $97 \% \mathrm{O}_{2}$ and $3 \% \mathrm{CO}_{2}$. Chemicals used were atropine sulphate and sodium nitroprusside (BDH Chemicals Ltd), D-arginine and L-arginine (Aldrich Chemical Company Inc), bovine haemoglobin, guanethidine monosulphate, $\mathrm{N}$-monomethyl-D-arginine acetate, $\mathrm{N}$-monomethyl-L-arginine acetate, $\mathrm{N}$-nitro-L-arginine, and tetrodotoxin (all from Sigma Chemicals Co).

Oxyhaemoglobin was prepared as described previously, ${ }^{26}$ by reduction of bovine haemoglobin (Sigma) with sodium hydrosulphite (10fold molar excess) followed by gel filtration with a prepacked disposable column (PD-10, Pharmacia), previously equilibrated with buffered Krebs solution. The concentration of oxyhaemoglobin was then determined spectrophotometrically $\left(E_{576 \mathrm{~nm}}=15.99 \mathrm{mM}^{-1} \mathrm{~cm}^{-1}\right)$. Methaemoglobin was made in a similar fashion, except that two fold molar excess of potassium ferricyanide was used instead of sodium hydrosulphite. ${ }^{27}$

Where appropriate, results are expressed as mean (SEM), and statistical differences were assessed with the unpaired $t$ test; a value of $\mathrm{p}<0.05$ was considered to be significant.

\section{Results}

RESPONSE TO SODIUM NITROPRUSSIDE

Sodium nitroprusside is an exogenous donor of $\mathrm{NO},{ }^{28}$ and its addition to the superfusate caused dose dependent relaxations $(n=18)$ (Fig 1). Sodium nitroprusside was applied for 60 seconds and a maximal response was achieved at a concentration of $5 \times 10^{-7} \mathrm{M}$, when the residual tone in the strips was equivalent to that present in calcium free solution (zero tone).

RESPONSE TO ELECTRICAL FIELD STIMULATION Muscle strips relaxed in response to electrical field stimulation using a pulse strength of $10 \mathrm{~V}$ and a pulse duration of $0.5 \mathrm{~ms}(n=24)$. The relaxations were frequency dependent, reaching a maximum at $8 \mathrm{~Hz}$. They could be repeated at three minute intervals (Fig 2). Responses occurred in the presence of atropine and guanethidine, and were all $(1-30 \mathrm{~Hz})$ abolished by tetrodotoxin
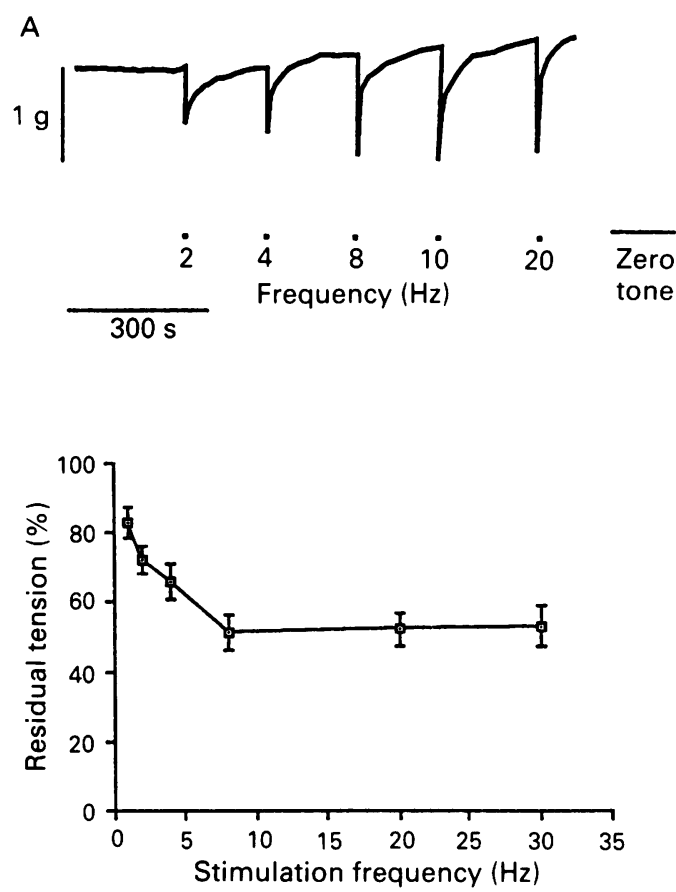

B

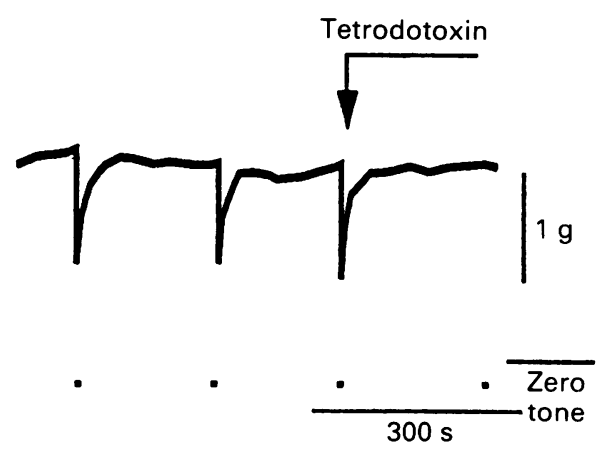

Figure 2: Response of isolated strips of internal anal sphincter to intrinsic nerve stimulation. (A) Relaxation produced and a frequency response curve. At each $\bullet$ impulses of $10 \mathrm{~V}$ were applied for $0.5 \mathrm{~ms}$ duration, and the frequency of stimulation increased from $0-30 \mathrm{~Hz}$. (B) Repeatable relaxations are produced if trains of impulses $(\bullet=10 \mathrm{~V}, 0.5 \mathrm{~ms}$ duration, $8 \mathrm{~Hz}$, for $1 \mathrm{~s}$ ) are applied every $180 \mathrm{~s}$. These occur in the presence of inhibitors of adrenergic and cholinergic neurotransmission, but are abolished by tetrodotoxin, $a$ universal nerve toxin. This implies that the relaxations are neurogenic and are mediated by NANC neurotransmitters. 


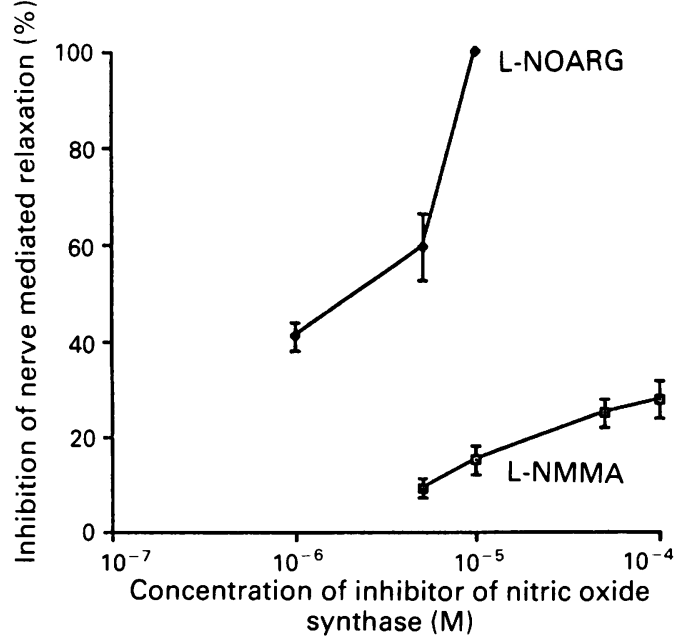

Figure 3: Effect of inhibitors of NO synthase on internal anal sphincter nerve mediated relaxation. Both are competitive antagonists but $N$-nitro-L-arginine (NOARG) is more potent than $N$-monomethyl-L-arginine $(L-N M M A)$.

$\left(3 \times 10^{-6} \mathrm{M}\right)$, a universal nerve toxin (Fig 2). This confirmed that the relaxations were neurogenic and mediated by a NANC neurotransmitter.

RESPONSE TO INHIBITORS OF NO SYNTHASE $\mathrm{N}$-monomethyl-L-arginine and $\mathrm{N}$-nitro-Larginine are synthetic analogues of $\mathrm{L}$-arginine, and competive antagonists of NO synthase. Figure 3 shows their dose dependent inhibition of internal anal sphincter nerve mediated relaxation (induced by electrical field stimulation $(\mathrm{n}=$ 18)).

At a concentration of $5 \times 10^{-5} \mathrm{M}, \mathrm{N}$-monomethyl-L-arginine produced a partial but significant inhibition of the nerve mediated relaxations, reducing them to $72 \cdot 4 \%(3.5 \%)$ of their original size $(n=22)(p<0 \cdot 05)$. Addition of D-arginine $\left(5 \times 10^{-4} \mathrm{M}\right)$ had no effect upon this inhibition, but it was reversed by $\mathrm{L}$-arginine at the same concentration (Fig 4). N-monomethyl$\mathrm{D}$-arginine, the enantiomer (steroisomer) of $\mathrm{N}$ monomethyl-L-arginine, had no effect upon the tissue.

$\mathrm{N}$-nitro-L-arginine is a more powerful antagonist of NO synthase. Its addition to the superfusate $\left(10^{-5} \mathrm{M}\right)$ abolished the response of the strips to electrical field stimulation $(n=30)$ (Fig 5). D-arginine $\left(5 \times 10^{-4} \mathrm{M}\right)$ had no effect upon this inhibition but it was reversed by the addition of $\mathrm{L}$-arginine at the same concentration (Fig 5).

EFFECT OF HAEMOGLOBIN

Oxyhaemoglobin has a high affinity for NO and scavenges it from extracellular media; methaemoglobin has no such action. ${ }^{27} 29$ Addition of oxyhaemoglobin produced inhibition of nerve mediated relaxation in a dose dependent manner $(n=6)$, and the neurogenic response was abolished at a concentration of $5 \times$ $10^{-5} \mathrm{M}(\mathrm{n}=20)$ (Fig 6). Relaxations returned after withdrawal of oxyhaemoglobin and a period of recovery (Fig 6). Methaemoglobin had no effect on the tissue.

\section{Discussion}

Enteric inhibitory nerves, similar to those that subserve the rectoanal inhibitory reflex, are found throughout the gastrointestinal tract and mediate relaxation in both sphincteric as well as non-sphincteric circular smooth muscle. They release NANC neurotransmitters and attention has previously concentrated on vasoactive intestinal polypeptide and adenosine triphosphate as the agents involved. ${ }^{30}$ To date however, satisfactory pharmacological evidence that either plays a part in neurogenic relaxation of the human internal anal sphincter has been lacking and the identity of the neurotransmitter responsible has remained obscure. ${ }^{56}$ The studies described here clearly indicate the involvement of NO in this process.

The hypothesis that NO or an NO-like substance is an enteric inhibitory neurotransmitter is based on the following evidence: (1) the enzyme responsible for NO production, NO synthase, has been shown within enteric neurons ${ }^{831} ;(2) \mathrm{NO}$ is released on stimulation of enteric inhibitory NANC nerves ${ }^{16} ;$; 3 ) there is a uniformity of action on gut smooth muscle when $\mathrm{NO}$ is applied from an exogenous source and when it is released by nerve stimulation ${ }^{15}{ }^{19}$; and agents that inhibit or potentiate the effect of inhibitory nerve stimulation have a similar action on exogenously applied NO.'

Conventional neurotransmitters such as acetylcholine and noradrenaline are stored in membrane bound vesicles before their release from presynaptic nerves, and they influence
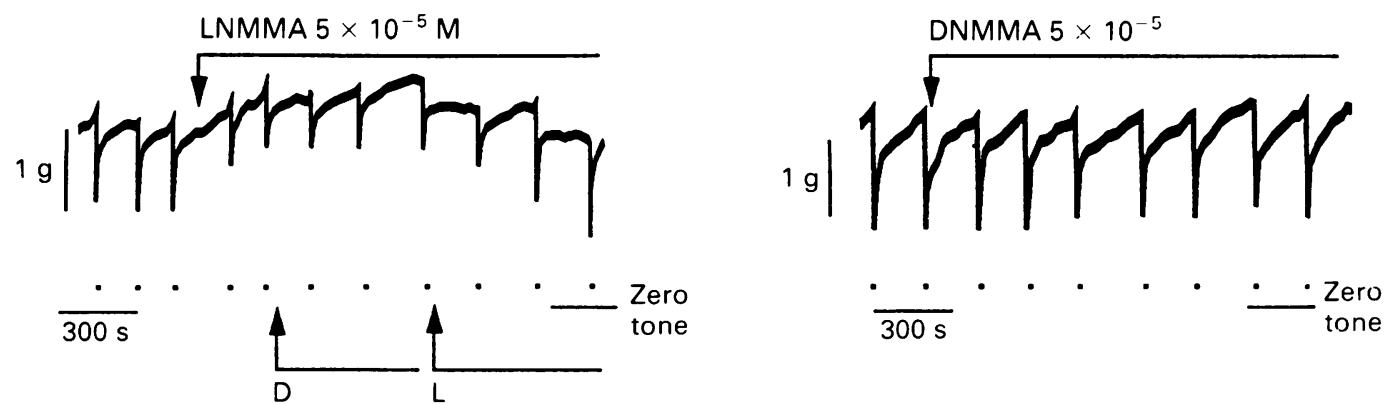

Figure 4: Effects of $N$-monomethyl-L-arginine $(L-N M M A)$ and $N$-monomethyl-D-arginine (D-NMMA) on internal anal sphincter nerve mediated relaxation $(\bullet=10 \mathrm{~V}, 0.5 \mathrm{~ms}$ duration, $8 \mathrm{~Hz}$, for $1 \mathrm{~s})$. The antagonistic action of $L$-arginine $(L)$, but not D-arginine $(D)$ is evident. 


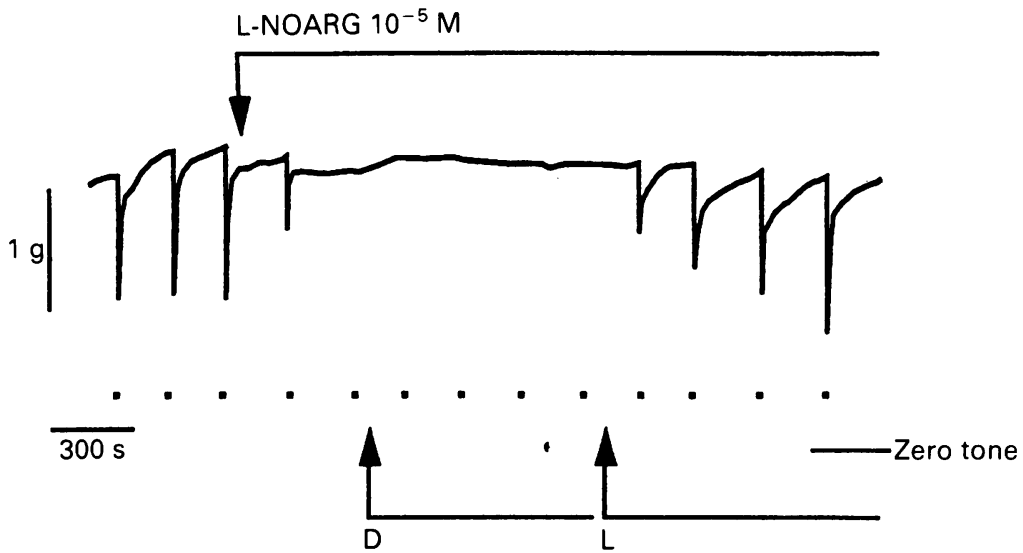

Figure 5: Effect of $N$-nitro-L-arginine (NOARG) on internal anal sphincter nerve mediated relaxation $(\bullet=10 \mathrm{~V}, 0.5 \mathrm{~ms}$ duration, $8 \mathrm{~Hz}$, for $1 \mathrm{~s})$. Its action is antagonised by L-arginine $(L)$, but not $D$-arginine $(D)$. evidence supporting this. ${ }^{32}$ Alternatively, NO could be produced on demand only, and it is conceivable that depolarisation makes calcium available for $\mathrm{NO}$ synthase activation within the presynaptic neuron. Another possibility is that depolarisation releases NO synthase into the synaptic cleft and it is this free enzyme that produces NO. This theory is improbable, however, as the proteolytic enzyme, $\alpha$-chymotrypsin, enhances rather than inhibits nerve mediated relaxation of the internal anal sphincter and this points against release of a peptide or protein. ${ }^{6}$

The mechanism by which NO causes smooth muscle relaxation has not yet been estalished. It is recognised that, by activating soluble guanylate cyclase, NO increases synthesis of cyclic guanosine monophosphate and this has been shown to produce membrane hyperpolarisation in colonic smooth muscle. ${ }^{33}$ Such membrane changes are the hallmark of NANC nerve mediated relaxation and are thought to result from an increase in potassium conductance. ${ }^{32}$ The processes responsible for electromechanical coupling have not been determined, but possible mechanisms include enhanced $\mathrm{Ca}^{2+}$ sequestration and reduced sensitivity of the contractile apparatus to $\mathrm{Ca}^{2+}$.

In the experiments described here, sodium nitroprusside, an exogenous source of NO, mimiced the effect of electrical field stimulation in producing relaxation of human internal anal sphincter smooth muscle. These neurogenic responses could be inhibited, and indeed abolished by antagonists of NO synthase. This action was dose dependent and enantiomer (stereoisomer) specific. Also, nerve mediated relaxations were inhibited by oxyhaemoglobin, which implies that NO passes extracellularly to exert its effects. Taken together, these results strongly indicate that in humans, NO mediates neurogenic relaxation of the internal anal sphincter and indeed, using the stimulation parameters described, there is no reason to suggest involvement of other neurotransmitters. Whether or not their presence can be completely excluded will depend on the results of subsequent studies in which the effects of a range of stimulation parameters will be examined.

Burleigh previously reported similar actions for $\mathrm{N}$-nitro-L-arginine and $\mathrm{L}$-arginine on neurogenic relaxation in human internal anal sphincter

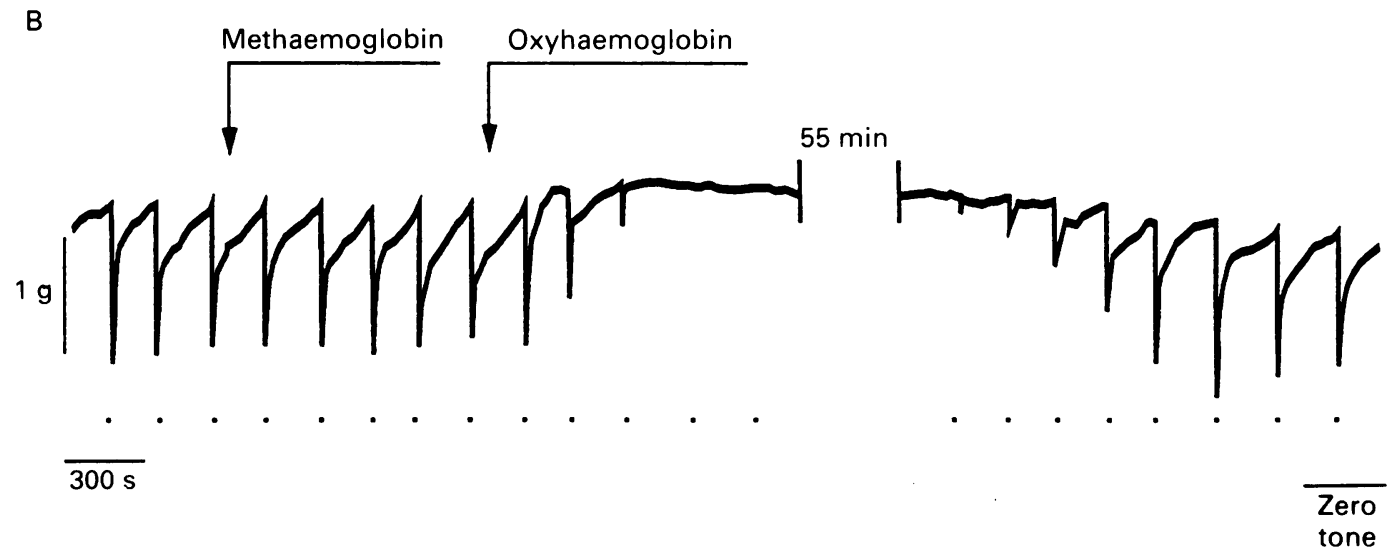


smooth muscle. ${ }^{25}$ To our knowledge however, the dose dependent effect of sodium nitroprusside, the enantiomeric specificity of the inhibition of NO synthase (and its reversal by substrates), and the action of oxyhaemoglobin have not been described in this tissue before.

Rattan and coworkers have investigated the role of NO in neurogenic relaxation of the internal anal sphincter in the opossum in vitro ${ }^{23}$ and have also assessed involvement of $\mathrm{NO}$ in the rectoanal inhibitory reflex in the same animal in vivo. ${ }^{24}$ In both preparations, NO seems to play a crucial part as $\mathrm{N}$-nitro-L-arginine has a profound antagonistic effect on inhibitory nerve stimulation. As in the human, this action is both dose and enantiomer specific. Although the opossum is phylogenically disparate from the human, these findings support our conclusions, particularly because they show the importance of NO in this region in vivo.

The immediate significance of establishing $\mathrm{NO}$ as the inhibitory neurotransmitter which mediates neurogenic relaxation of the human internal anal sphincter is that it will allow detailed study of the function and morphology of the intrinsic innervation of this tissue as well as its interaction with other components of the autonomic nervous system. These aspects of sphincter physiology can be assessed both in vitro and in vivo, and will not only improve our understanding of normal internal anal sphincter function, but will also shed new light on the pathophysiology of conditions such Hirschsprung's disease $\mathrm{s}^{34}$ and idiopathic anorectal incontinence, in which the intrinsic innervation of the internal anal sphincter is known to be abnormal..$^{35}$ Also, it may prove possible to manipulate NO neurotransmission pharmacologically, either inhibiting or enhancing it, and this could have important therapeutic implications in the management of disordered anorectal function.

This research was financed and supported by The Wellcome Trust.

1 Gowers WR. The automatic action of the sphincter ani. Proc $R$ Soc Lond 1887; 26: 77-84.

2 Denny-Brown D, Robertson EG. An investigation of the nervous control of defaecation. Brain 1935; 58: 256-310

3 Garrett JR, Howard ER, Jones W. The internal anal sphincter in the cat: a study of the nervous mechanisms affecting tone and reflex activity. $\mathcal{F}$ Physiol 1974; 243: 153-66.

4 Lubowski DZ, Nicholls RJ, Swash M, Jordan MJ. Neural control of internal anal sphincter function. Br $\mathcal{F}$ Surg 1987; 74: 668-70.

5 Burleigh DE, D'Mello A, Parks AG. Responses of isolated human internal anal sphincter to drugs and electrical field human internal anal sphincter to drugs and el
stimulation. Gastroenterology 1979; 77: 484-90.

6 Burleigh DE. Non-adrenergic non cholinergic inhibitory neurons in the human internal anal sphincter muscle. f Pharm Pharmacol 1983; 35: 258-60.

7 Moncada S, Palmer R UJ, Higgs EA. Nitric oxide: physiology, pathophysiology al 'pharmacology. Pharmacol rev 1991; 43: $109-42$.

8 Vincent SR, Hope BT. Neurons that say NO. Trends Neurosci 1992; 15: 108-13.
9 Sanders KM, Ward SM. Nitric oxide as a mediator of nonadrenergic noncholinergic neurotransmission. Am $\mathcal{J}$ Physiol 1992; 262: G379-92.

10 Murray J, Du C, Ledlow A, Bates JN, Conklin JL. Nitric oxide: mediator of nonadrenergic noncholinergic responses of opossum esophageal muscle. Am f Physiol 1991; 261: G401-6.

11 Tottrup A, Svane D, Forman A. Nitric oxide mediating NANC inhibition in opossum lower esophageal sphincter. Am F Physiol 1991; 260: G385-9.

12 Desai KM, Sessa WC, Vane JR. Involvement of nitric oxide in the reflex relaxation of the stomach to accomodate food or fluid. Nature 1991; 351: 477-9.

13 Boeckxstaens G, Pelckmans PA, Bogers, et al. Release of nitric oxide upon stimulation of nonadrenergic noncholinergic nerves in the rat gastric fundus. $\mathcal{F}$ Pharmacol Exp Ther 1990 256: 441-7.

14 Maggi CA, Barbanti G, Turini D, Guiliani S. Effect of $\mathrm{N}$-monomethyl-L-arginine (L-NMMA) and N-Nitro-Larginine (L-NOARG) on nonaderenergic noncholinergic relaxation in the circular muscle of the human ileum. $\mathrm{Br} f$ Pharmacol 1991; 103: 1970-2.

15 Boeckxstaens G, Pelckmans PA, Bult H, de Man JG, Herman AG, Van Maercke YM. Non adrenergic non cholinergic relaxation mediated by nitric oxide in the canine ileocolonic relaxation mediated by nitric oxide in the canin
junction. Eur $\mathcal{F}$ Pharmacol 1990; 190: 239-46.

16 Bult H, Boeckxstaens G, Pelckmans PA, Jordaens FH, Van Maercke YM, Herman AG. Nitric oxide as an inhibitory non adrenergic non cholinergic neurotransmitter. Nature 1990 345: $246-7$.

17 Huizinga JD, Tomlinson J, Pintin-Quezada J. Involvement of nitric oxide in nerve mediated inhibition and action of vasoactive intestinal peptide in colonic smooth muscle. f Pharmacol Exp Ther 1992; 260: 803-8.

18 Dalziel HH, Thornbury KD, Ward SM, Sanders KM Involvement of nitric oxide synthetic pathway in inhibitory junction potentials in canine proximal colon. Am $\mathcal{f}$ Physiol 1991; 260: G789-92.

19 Ward SM, Dalziel HH, Thornbury KD, Westfall DP, Sanders KM. Nonadrenergic, noncholinergic inhibition and rebound excitation in canine colon depend on nitric oxide. rebound excitation in canine colo

20 Craig JW, Muir TC. Nitric oxide in inhibitory transmission in the guinea-pig internal anal sphincter. Br f Pharmacol 1991 104: $6 \mathrm{P}$.

21 O'Kelly TJ, Brading AF, Mortensen NJ. Inhibitory transmission in isolated pig internal anal sphincter: the role of nitric oxide. F Physiol 1992; 446: 523P.

22 Tottrup A, Glavind EB, Svane D. Involvement of the L-arginine-nitric oxide pathway in internal anal sphincter relaxation. Gastroenterology 1992; 102: 409-15.

23 Rattan S, Chakder S. Role of nitric oxide as a mediator of internal anal sphincter relaxation. Am 7 Physiol 1992; 262 G107-12.

24 Rattan S, Sarkar A, Chakder S. Nitric oxide pathway in rectoanal inhibitory reflex of opossum internal ana sphincter. Gastroenterology 1992; 103: 43-50.

25 Burleigh DE. N-nitro-L-arginine reduces nonadrenergic noncholinergic relaxation of the human gut. Gastroenterology 1992; 102: 679-83.

26 Salvemini D, De Nucci G, Gryglewski RJ, Vane J. Human neutrophils and mononuclear cells inhibit platelet aggregation by releasing a nitric oxide-like substance. Proc Nat Acad Sci 1989; 86: 6328-32.

27 Martin W, Smith J, White DG. The mechanism by which haemoglobin inhibits the relaxation of rabbit aorta induced by nitrovasodilators, nitric oxide or bovine retractor penis by nitrovasodilators, nitric oxide or bovine retract

28 Feelisch M, Noack EA. Correlation between NO formation during degradation of organic nitrates and activation of guanylate cyclase. Eurf P harmacol 1987; 139: 19-30.

29 Salvemini D, Radziszewski W, Korbut R, Vane J. The use of oxyhaemoglobin to explore the events underlying inhibition of platelet aggregation induced by nitric oxide or nitric oxide donors. Br F Pharmacol 1990; 101: 991-5.

30 Furness JB, Costa M. Enteric neurotransmitters. In: Furness JB, Costa M, eds. The enteric nervous system. Edinburgh: Churchill-Livingstone, 1987: 55-89.

31 Bredt S, Hwang PM, Snyder SH. Localization of nitric oxide synthase indicating a neural role for nitric oxide. Nature 1990; 347: 768-70.

32 Thornbury KD, Ward SM, Dalziel HH, Carl A, Westfall DP, Sanders KM. Nitric oxide and nitrosocysteine mimic nonadrenergic, noncholinergic hyperpoloarisation in canine adrenergic, noncholinergic hyperpoloarisation

33 Ward SM, McKeen ES, Sanders KM. Role of nitric oxide in non-adrenergic, non-cholinergic inhibitory junction potentials in canine ileocolinic sphincter. Br f Pharmacol 1992; 105: 776-82.

34 Callaghan RP, Nixon HH. Megarectum: physiological observations. Arch Dis Child 1964; 39: 153-7.

35 Speakman CTM, Kamm MA. The internal anal sphincternew insights into faecal incontinence. Gut 1991; 32: 345-6. 